\title{
BOEKBESPREKING \\ FIFTEEN GOLDEN EXAMPLES: INDIAN TEMPLE ARCHITECTURE IN KARNATAKA
}

Als ik aan Karnataka denk, zie ik diepgroene koffieplantages in de heuvels en de enorme rode rotsblokken hier en daar verspreid op het Deccan-plateau. Karnataka, met zijn ruige landschap, behoort tot een van mijn favoriete streken van India. Wat deze regio voor een architectuurliefhebber echter zo interessant maakt is niet de natuur maar de grote concentratie van hindoetempels die bovendien tot de mooiste van India gerekend kunnen worden. Ondanks de herhaaldelijke veldtochten van de moslims, die in deze streek vanaf de $14^{\mathrm{e}}$ eeuw plaatsvonden, zijn de tempels van Karnataka bijna ongedeerd gebleven.

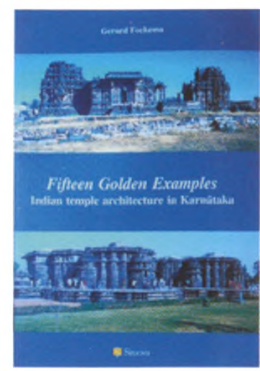

De deelstaat Karnataka ligt in het centrale gedeelte van het Indiase subcontinent en is daardoor een ontmoetingsplaats van de twee voornaamste bouwstijlen in de Indiase tempelarchitectuur: de noordelijke stijl, ook Nagara genoemd, en de zuidelijke stijl, bekend als Dravida. Deze stijlen verschillen nogal van elkaar en deze verschillen zijn, ook voor een leek, vooral zichtbaar in de vorm van de tempeltoren. In de Noord-Indiase Nagara-stijl is de tempeltoren (in deze stijl sikhara genoemd) heel hoog. Het is meestal het hoogste punt van de hele tempel. Op de top van de tempeltoren bevindt zich een ronde platte steen, de amalaka (genoemd naar een vrucht met exact dezelfde vorm), en daarboven een potvormig element (kalasha). In de ZuidIndiase Dravida stijl daarentegen is de bovenbouw van de tempel (hier vimana genoemd) lager en lijkt meer op een piramide dan op een toren. Hij bestaat uit steeds kleinere verdiepingen (tala of bhumi), bekroond met een achthoekig, rond of vierkant element dat in Zuid-India shikhara heet. Een Dravida-tempel wordt omringd door tempelmuren met poorten op de vier windrichtingen, de gopuras. De gopuras zijn, zeker in de latere periode, hoger dan de tempeltoren zelf en vormen daardoor het hoogste element van een tempelcomplex.

De centraal gelegen Karnataka vormt het grensgebied tussen deze twee stijlen. Daarom is het alleen in Karnataka mogelijk om grote aantalen noordelijke èn zuidelijke tempels naast elkaar te bewonderen. Bovendien, alweer door de geografische ligging, heeft zich in Karnataka een aparte stijl ontwikkeld die de kenmerken van de Noord-Indiase Nagara en de Zuid-Indiase Dravida-stijlen combineert. Deze eclectische stijl is bekend als Vesara. Zeer karakteristiek van deze mengstijl zijn de miniatuurafbeeldingen van tempeltorens die ter decoratie aan de buitenkant van de tempelmuren afgebeeld werden, vooral boven de nissen (afb. 1 en 2 ).

Alleen dit al maakt Karnataka een bijzonder gebied voor degenen die geïnteresseerd zijn in de Indiase kunst en architectuur. Maar Karnataka kent meer :17 AM tempels die voor de geschiedenis van de Indiase tempelarchitectuur niet ee access 
Afbeelding 2

Kasivisvesvara tempel, Lakkundi. Detail. Foto: Gerard Foekema.

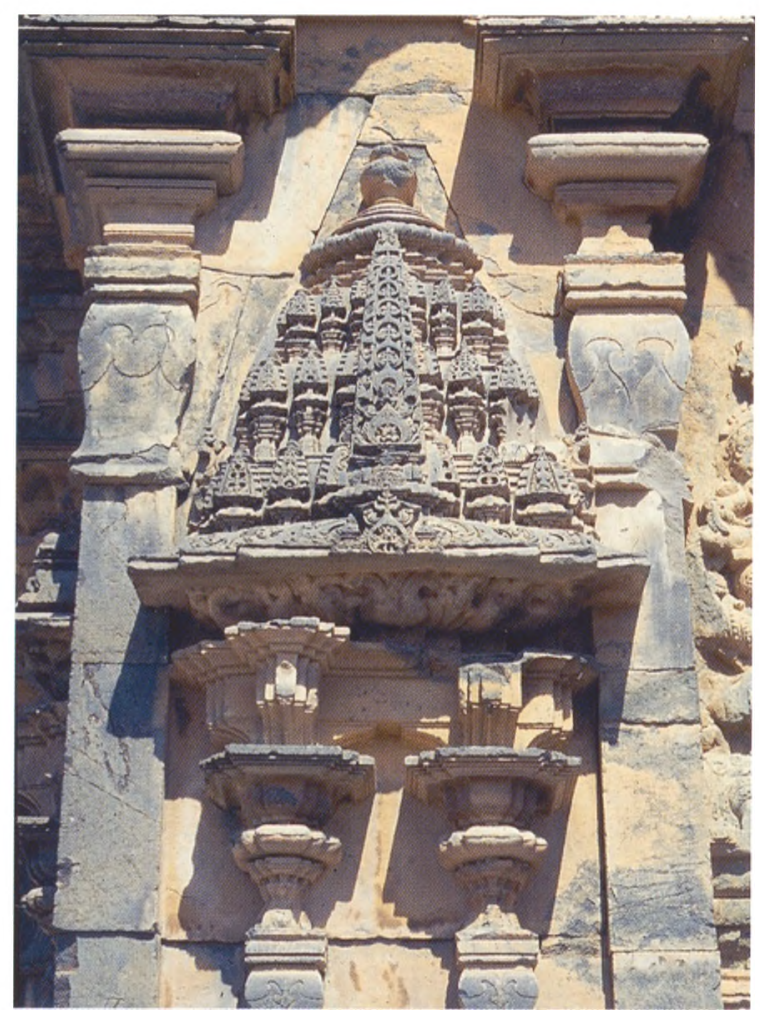

onbelangrijk zijn. Een paar van de vroegste Indiase tempels bevinden zich in Karnataka - in Badami, Aihole, Mahakuta en Pattadakal. Zij stammen uit de laat $6^{\mathfrak{e}}, 7^{\mathfrak{C}}$ en $8^{\mathrm{e}}$ eeuw en werden gebouwd tijdens de heerschappij van de vroege Westelijke Calukya-dynastie. Bovendien is de regio een bakermat van de bekende Hoysala-stijl, genoemd naar een dynastie die tussen de $11^{\mathrm{e}}$ en de $14^{\mathrm{e}}$ eeuw in de Deccan heerste. Deze stijl wordt ook Indiase barok genoemd omdat de tempels uit deze periode bijzonder rijk gedecoreerd werden. Men kan hier zeker van horror vacui spreken - geen enkel gedeelte van een Hoysala-tempel is onversierd gelaten (afb. 3).

Het prachtig geillustreerde boek van Gerard Foekema beschrijft 15 verschillende hindoetempels van Karnataka uit de periode van de $8^{\mathrm{c}}$ tot de $16^{\mathrm{e}}$ eeuw. Sommige van deze tempels, zoals bijvoorbeeld de Durga-tempel in Aihole (Aivalli) en de Kesava-tempel in Somnathpur, zijn bekende monumenten en worden genoemd in vele publicaties over Indiase tempelarchitectuur. Andere, die buiten de bekende plaatsen liggen, zoals bijvoorbeeld de Mallikarjunatempel in Sudi, zijn vooral bij specialisten bekend. Niet alle beschreven tempels zijn nog in gebruik en maken een verlaten indruk.

Het boek bestaat uit 15 hoofdstukken voorafgegaan door een inleidend gedeelte met daarin een beknopte beschrijving van de architectuurstijlen die onder bepaalde locale dynastieën tot stand kwamen. Elk hoofdstuk beschrijft één tempel, in chronologische volgorde.

De onderverdeling van de hoofdstukken kent een vast patroon. Elk hoofdstuk begint met een korte beschrijving van de tempellocatie gevolgd door de 08:45:17 Am informatie, voor zover bekend, over de bouwdatum en de opdrachtgeveree access 
Daarna volgt een systematische beschrijving van de tempel beginnend met het grondplan en eindigend met de decoratieve elementen inclusief de afbeeldingen van de hindoegoden die vooral naast de ingang en op de buitenkant van de tempelmuren afgebeeld werden. Als laatste wordt, ter vergelijking, een lijst van monumenten gegeven die qua stijl dicht bij de beschreven tempel staan. Het hele boek is rijk geillustreerd en de foto's (allemaal in kleur) zijn van goede kwaliteit. Bij elke beschreven tempel hoort een tekening van de plattegrond en van de elevatie plus een aantal foto's, waarvan één altijd het hele gebouw laat zien, van basis tot en met de bovenbouw, wat een goede indruk geeft van de verschillen tussen de stijlen. Achterin het boek vindt men nog een aantal handige plattegronden van Karnataka met daarop de tempellocaties.

Het boek van Foekema geeft dankzij de nauwkeurige beschrijvingen en de goede foto's en plattegronden een goede indruk van de verscheidenheid en

Afbeelding 3

Hoysalesvara tempel, Halebid. Foto: Gerard Foekema.

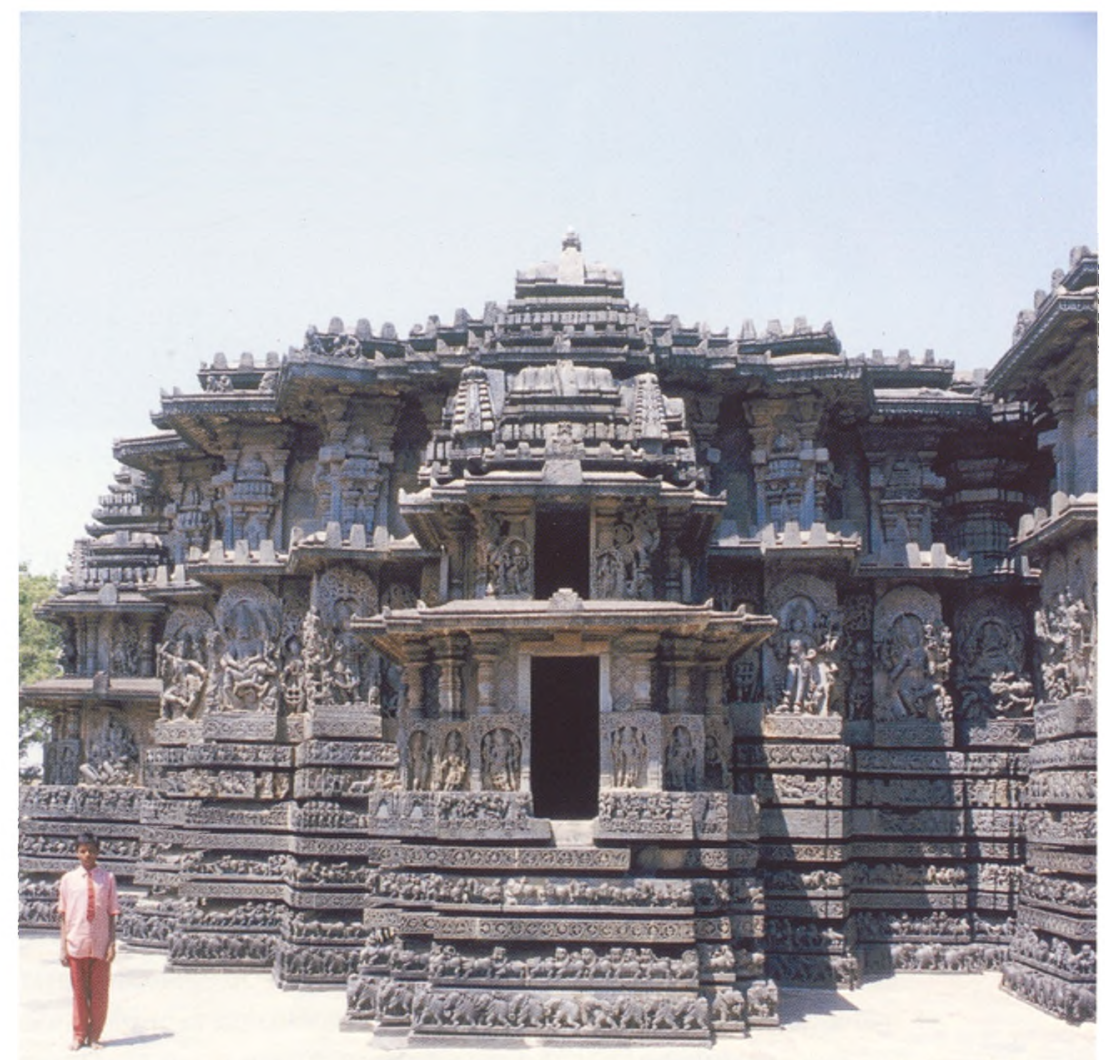




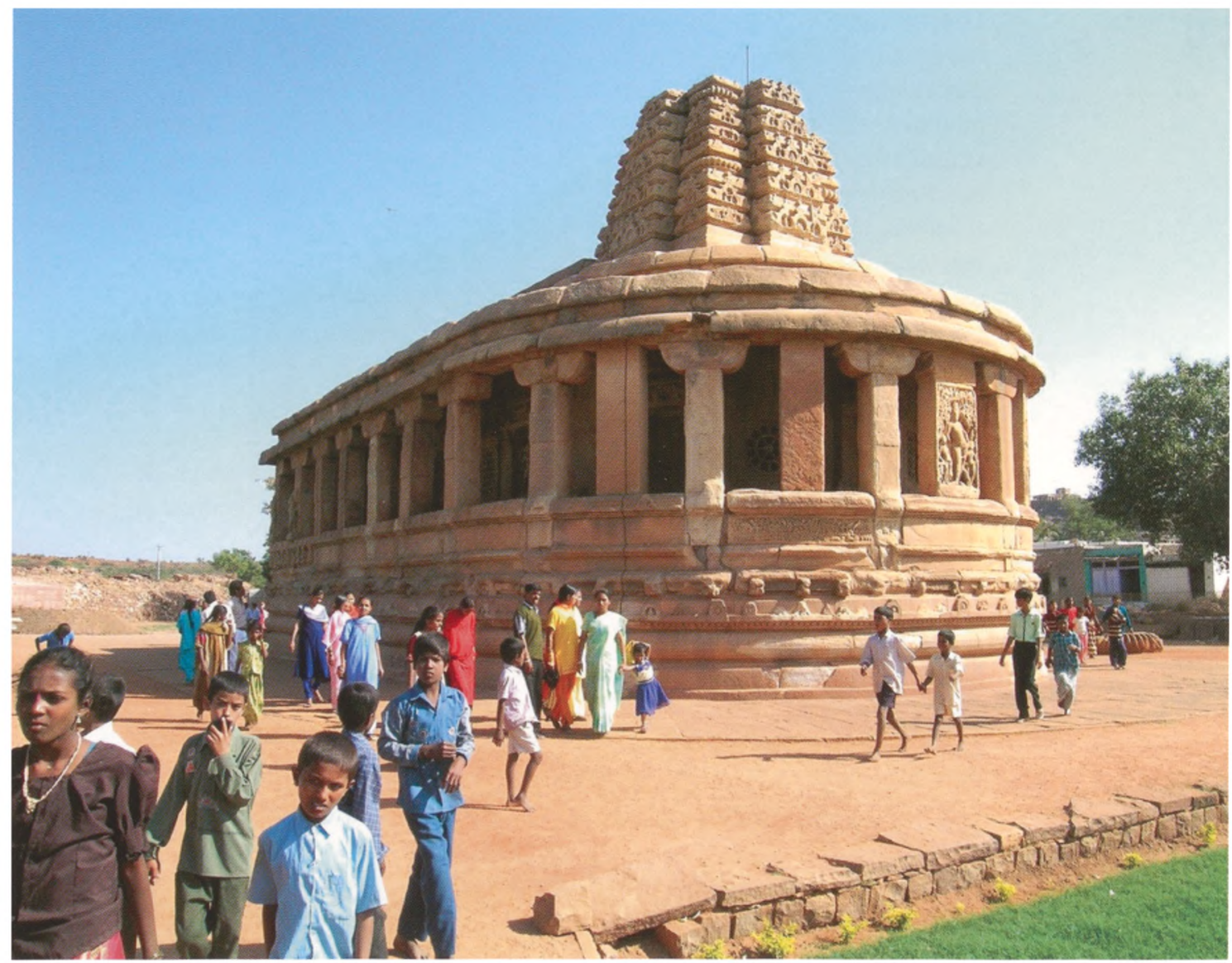

Afbeelding 4

Durga-tempel, Aihole (Aivalli). Foto: Gerard Foekema. het kunsthistorisch belang van de tempels in Karnataka - van de vroegste tempels in Aihole en Badami, via de eclectische Vesara-gebouwen en de rijk versierde Hoysala-tempels, tot de latere monumenten uit de tijd van het Vijayanagara-rijk. Het is echter meer een catalogus dan een kunsthistorische studie. In de inleiding en in de tempelbeschrijvingen wordt aan de ene kant veel aandacht besteed aan het feit dat deze tempels, en de hindoetempels in het algemeen, zeer vaak met architectonische elementen in miniatuur versierd werden. Aan de andere kant worden verdere belangrijke kenmerken van deze tempels vaak niet genoemd of niet voldoende benadrukt. Zo zou bij de beschrijving van de Durga-tempel in Aihole bijvoorbeeld nog toegevoegd kunnen worden dat vooral de combinatie van de apsidale basis met een 'gewone', in dit geval Noord-Indiase, tempeltoren zeer bijzonder is (afb. 4). Bij een apsidale tempel zou men helemaal geen toren maar eerder een hastiprishtha of 'olifantenrug-dak' verwachten. Verder zou bij sommige tempels, zoals de Kasivisvesvara in Lakkundi en de Kesava in Somnathpur, toegevoegd kunnen worden dat meer garbhagrhas (sanctum sanctorum; de Kasivisvesvara heeft er twee, de Kesava niet minder dan drie) een bekend verschijnsel is in Karnataka, maar dat dit buiten deze regio heel zeldzaam is. Als laatste mist meer uitgebreide informatie over de zeer bijzondere eclectische elementen, zowel in de introductie als in de afzonderlijke beschrijvingen. 
Toch is deze publicatie zeker een goede aanvulling op de 'klassieke' boeken over de tempelarchitectuur in India en zeker een waardevolle aanwinst voor de liefhebber van Indiase kunst. Wat deze publicatie zo aardig maakt - naast de foto's en plattegronden - zijn de persoonlijk getinte, levendige passages waarin de auteur zijn eigen indruk geeft van de tempels en hun omgeving. Het is goed te zien dat de auteur zelf de plaatsen bezocht heeft en dat hij ze goed kent. Daarnaast vindt men in het boek ook de nodige praktische informaties over entreegelden en dergelijke. Het boek van Foekema is daarom goed te gebruiken als een aanvulling op een reisgids voor Karnataka. Het is een ieder aan te bevelen met dit boek in de hand de tempels zelf te bezoeken.

- Gerard Foekema

Fifteen Golden Examples: Indian Temple Architecture in Karnataka

Simova, Bangalore 2005

181 paginas, 280 kleurenillustraties

ISBN 81-7878-009-7 